\title{
Genetic Divergence in Bottle Gourd [Lagenaria siceraria (Mol.) Stand.]
}

\author{
A. K. M. Quamruzzaman \\ Olericulture Division, Horticulture Research Centre, Bangladesh Agricultural Research Institute, Gazipur-1701, \\ Bangladesh \\ Email: akmqzs@gmail.com
}

\begin{abstract}
An experiment was conducted at the experimental field of Olericulture Division, Bangladesh Agricultural Research Institute, Bangladesh during the winter season of 2017-18. Twenty two bottle gourd genotypes were evaluated to genetic diversity. The genotypes were clustered into five distinct groups with the range of 1 genotypes to 8 . The inter-cluster distance in all cases was larger than the intra-cluster distance suggesting wider genetic diversity among the genotypes of different groups. The maximum inter-cluster distance was observed between genotypes of cluster III and IV (15.010) followed by cluster II and IV (12.841) and the minimum was found between genotypes of cluster II and III (5.318). The highest intra cluster value (0.933) was observed in cluster I due to the presence of variations among the genotypes.
\end{abstract}

Keywords: genetic divergence, intra-cluster and inter-cluster distances, bottle gourd

\section{Introduction}

Bottle gourd [Lagenaria siceraria (Mol.) Stand.] is a popular winter vegetable in Bangladesh. Its cultivation and uses are wide in winter but now a days it is cultivating during summer and rainy season. In respect of total acreage of bottle gourd is 7,217 ha and production are 85,267 ton in Bangladesh with an average yield of 11.81 tons per hectare (Anon., 2017), which is very low. Various types of bottle gourd are grown by the farmers in the different parts of the country with various local names such as Lau, Panilau, Khetlau, Kadu etc. It belongs to the family Cucurbitaceae. Significant variation of plant type, fruit type, fruit shape, fruit colour is found among the available genotypes. Comprehensive information of the nature of genetic divergence of the genotypes is the prerequisite of a variety development programme. The quantification of genetic diversity through biometrical procedures has made it possible to choose genetically diverge parents for a successful hybridization programme. Multivariate analysis by means of Mahalanobis $\mathrm{D}^{2}$ statistics is an useful tool in quantifying the degree of genotypic divergence among biological populations and helps in selecting desirable parents for achieving desired goal by the breeder.

To carry out any successful breeding programme, it is necessary to select suitable parental lines from available indigenous germplasms. The study of genetic divergence is a popular method in parent selection for researchers involved in breeding programs of several crops, leading to reduce the number of crosses (Guerra et al. 1999). The progenies derived from diverse parents are expected to show a broad spectrum of genetic variability and provide better scope to isolate superior recombinants. Therefore, genetically diverse genotypes should be used in a hybridization program to get superior recombinants. The multivariate analysis is the most widely used statistical tools to quantify the genetic divergence. Among the various methods developed to study the genetic divergence in the genotypes/accessions, the Mahalanobis $\mathrm{D}^{2}$ (Mahalanobis, 1936) is the most reliable and widely used statistical tools to quantify the degree of genetic divergence by assessing the relative contribution of different characters to the total divergence. It is a very useful technique and has been used by several workers in case of self-pollinated or cross pollinated crops (Bashar et al., 2016; Hasan et al., 2015; Huque et al., 2012; Natarajan et al., 1988; Shidhu et al., 1989). Relative contribution of different traits to the total divergence helps to select a particular trait or a combination of traits for intercrossing which avoids wastage to time and labor. Principal component analysis (PCA) is also a powerful technique which allows the visualization of natural grouping of the genotypes and is precise indicator of differences among genotypes (Huque et al., 
2012). More stable genotypes are believed to generate superior recombinants through crossing as there is less environmental influence on them. Therefore, the present investigation was undertaken to estimate the nature and magnitude of genetic diversity in some local bottle gourd genotypes in Bangladesh condition.

\section{Materials and Method}

The experiment was conducted at the experimental field of Olericulture Division, Horticulture Research Center (HRC), Bangladesh Agricultural Research Institute (BARI), Gazipur during the winter season of 2017-18. Twenty days old seedlings were transplanted in the main field on 4 Nov 2006 in a RCB design with three replications. The unit plot size was $10.0 \times 2.0 \mathrm{~m}$. The land was fertilized with cow dung, urea, TSP, MP, Gypsum and zinc @ 10000, 175, 175, 150, 100 and $12 \mathrm{~kg} / \mathrm{ha}$, respectively. The intercultural operations (weeding and irrigation etc.) were done as and when necessary. Data on 13 characters (Table 3) were recorded from three selected plants per entry per replication. Plot means over the replications were used for the statistical analysis. Genetic diversity (Mahalanobis, 1936), generalized distance $\left(\mathrm{D}^{2}\right)$ and clustering(Rao, 1952), calculating intra and inter cluster distances (Singh and Chaudhury, 1985) were studied. Statistical analyses were carried out using Genstat 5 software.

\section{Results and Discussion}

Based on the degree of divergence 22 genotypes were grouped into five clusters (Table 1). The distribution pattern revealed that maximum number of genotypes (8) was included in cluster $\mathrm{V}$ followed by cluster I and cluster II (5 genotypes each) and cluster III (3 genotypes), while cluster IV included the minimum (1 genotype). Similar result was found by Indra et al. (2000), Sreelathakumary and Rajmony (2004), Farhad et al. (2010), Datta and Jana (2011), Datta and Das (2013) and Yatung et al. (2014).

Table 1. Distribution of 22 genotypes of bottle gourd in different clusters

\begin{tabular}{ccl}
\hline Cluster & $\begin{array}{c}\text { Number of } \\
\text { genotypes }\end{array}$ & Genotypes (Source/ place of collection) \\
\hline I & 5 & $\begin{array}{l}\text { LS03 (BARI, Bangladesh), LS04 (India), LS05 (India), LS06 (BARI, Bangladesh), LS07 } \\
\text { (Dhaka, Bangladesh) }\end{array}$ \\
II & 5 & $\begin{array}{l}\text { LS01 (BARI Lau-1), LS08 (Narshindi, Bangladesh), LS10 (Chittagong, Bangladesh), LS13 } \\
\text { (Rangpur, Bangladesh), LS14 (Jessore, Bangladesh) }\end{array}$ \\
III & 3 & $\begin{array}{l}\text { LS09 (Comilla, Bangladesh), LS11 (Sherpur, Bangladesh), LS12 (Bogra, Bangladesh) } \\
\text { IV }\end{array}$ \\
VS02(BARI Lau-2) & LS15 (Gazipur, Bangladesh), LS16 (Sherpur, Bangladesh), LS17 (Natore, Bangladesh), \\
LS18 (Rajshahi, Bangladesh), LS19 (Naogaon, Bangladesh), LS20 (Comilla, Bangladesh), \\
LS21 (Jessore, Bangladesh), LS22 (Jamalpur, Bangladesh)
\end{tabular}

Table 2. Mean intra- (bold) and inter- cluster distances $\left(\mathrm{D}^{2}\right)$ for the twenty two bottle gourd genotypes

\begin{tabular}{cccccc}
\hline Cluster & I & II & III & IV & V \\
\hline I & $\mathbf{0 . 9 3 3}$ & 7.627 & 7.947 & 10.678 & 9.056 \\
II & & $\mathbf{0 . 8 4 8}$ & 5.318 & 12.841 & 11.834 \\
III & & $\mathbf{0 . 5 5 3}$ & 15.010 & 11.021 \\
IV & & & $\mathbf{0 . 0 0}$ & 10.443 \\
V & & & & $\mathbf{0 . 2 1 1}$ \\
\hline
\end{tabular}

The maximum inter-cluster distance were recorded between the cluster III and IV (15.010) followed by the distance between II and IV (12.841) (Table 2). As the genetic variation is very distinct among the groups, genotypes from these five clusters if used in hybridization, may produce a wide spectrum of segregating population. The lowest inter cluster distance was observed between cluster II and III (5.318). 
However, the intra-cluster divergence varied from 0.000 to 0.933 , maximum being from cluster I that comprised of five genotypes, while the minimum distance was observed in cluster IV that comprised of one genotype.

Differences were observed in cluster means for almost all the thirteen characters in the 22 genotypes studied (Table 3). Cluster I composed of five genotypes and showed highest mean for branches per plant (30.07). On the other hand, this cluster also possessed least mean value for days to edible fruit maturity (16.60 days), while cluster II composed of five genotypes and was found second highest mean from days to edible fruit maturity (19.73 days).Cluster III composed of 3 genotypes and was found to score highest mean for days to fruit maturity (20.66 days), fruiting duration (53.11days) and least mean value of days to $1^{\text {st }}$ harvest (55.33). Cluster IV composed of only one genotype and was observed to score highest mean for days to $1^{\text {st }}$ harvest (84.33 days), TSS $(3.35 \%)$, vine length $(7.53 \mathrm{~m})$, fruits per plant (12.67), yield per plant $(28.95 \mathrm{~kg})$. These results indicated that this cluster possessed such characters which were responsible for higher yield, while cluster $\mathrm{V}$ composed of eight genotypes and was found to score highest mean for the characters fruit length $(47.32 \mathrm{~cm})$, fruit diameter $(16.12 \mathrm{~cm})$, fruit exocarp thickness $(2.18 \mathrm{~cm})$, fruit endocarp thickness $(11.76 \mathrm{~cm})$, fruit weight $(2.44 \mathrm{~kg})$. Jagadev et al. (1991) reported that the characters contributing maximum to the divergence should be given greater emphasis for deciding the type of cluster for the purpose of further selection and the choice of parents for hybridization.

Table 3. Class mean values of thirteen characters in 22 genotypes of bottle gourd

\begin{tabular}{lccccc}
\hline Characters & \multicolumn{5}{c}{ Cluster } \\
\cline { 2 - 6 } & $\mathrm{I}$ & $\mathrm{II}$ & $\mathrm{III}$ & $\mathrm{IV}$ & $\mathrm{V}$ \\
\hline Days to $1^{\text {st }}$ harvest & 60.47 & 58.33 & 55.33 & 84.33 & 73.50 \\
Days to edible fruit maturity & 16.60 & 19.73 & 20.66 & 18.33 & 19.17 \\
Fruiting duration (days) & 52.00 & 37.53 & 53.11 & 39.67 & 49.29 \\
Fruit length (cm) & 43.10 & 38.53 & 43.04 & 36.08 & 47.32 \\
Fruit diameter (cm) & 12.94 & 11.47 & 11.89 & 14.00 & 16.12 \\
Fruit exocarp thickness (cm) & 2.10 & 1.99 & 2.07 & 1.95 & 2.18 \\
Fruit endocarp thickness (cm) & 8.73 & 7.48 & 7.76 & 10.07 & 11.76 \\
TSS (\%) & 3.15 & 3.05 & 3.00 & 3.35 & 2.95 \\
Branches per plant & 30.07 & 25.27 & 19.67 & 27.67 & 21.29 \\
Vine length (m) & 7.31 & 7.25 & 6.04 & 7.53 & 6.63 \\
Fruits per plant & 11.73 & 11.53 & 8.89 & 12.67 & 8.33 \\
Fruit weight (kg) & 2.06 & 2.03 & 2.00 & 2.28 & 2.44 \\
Yield per plant $(\mathrm{kg})$ & 24.42 & 23.44 & 17.99 & 28.95 & 20.14 \\
\hline
\end{tabular}

Based on principal component axes I and II, a two-dimensional scattered plotting diagram $\left(\mathrm{Z}_{1}\right.$ and $\left.\mathrm{Z}_{2}\right)$ reflecting the position of genotypes are presented in Figure 1. It was revealed that from the diagram there were mainly five clusters. Most distantly located genotypes in cluster were III and cluster IV followed by cluster II and cluster IV. So there is a chance to obtain higher heterosis by crossing these clusters.

Contribution of characters towards divergence of the genotypes is presented in Table 4. The results of the PCA revealed that in vector I, the important characters responsible for genetic divergence in the major axis of differentiation were days to edible fruit maturity, fruiting duration and TSS having positive vector values. While in vector II branches per plant, vine length, fruits per plant and yield per plant having positive vector values was important. Quamruzzaman et al. (2008b) reported that days to $1^{\text {st }}$ female flower open, fruit diameter, single fruit weight and fruits per plant contributing major portion of the total genetic diversity in ridge gourd. In other study Quamruzzaman et al. (2008a) reported fruits per plant and fruit yield per plant contribute towards divergence in bitter gourd. Masudet al. (1995) found that number of fruits per plant and yield per plant was one of the important contributors to genetic divergence in pumpkin. Hence, these characters could offer a scope for genetic improvement and deserve to be included as selection criteria in bottle gourd. 


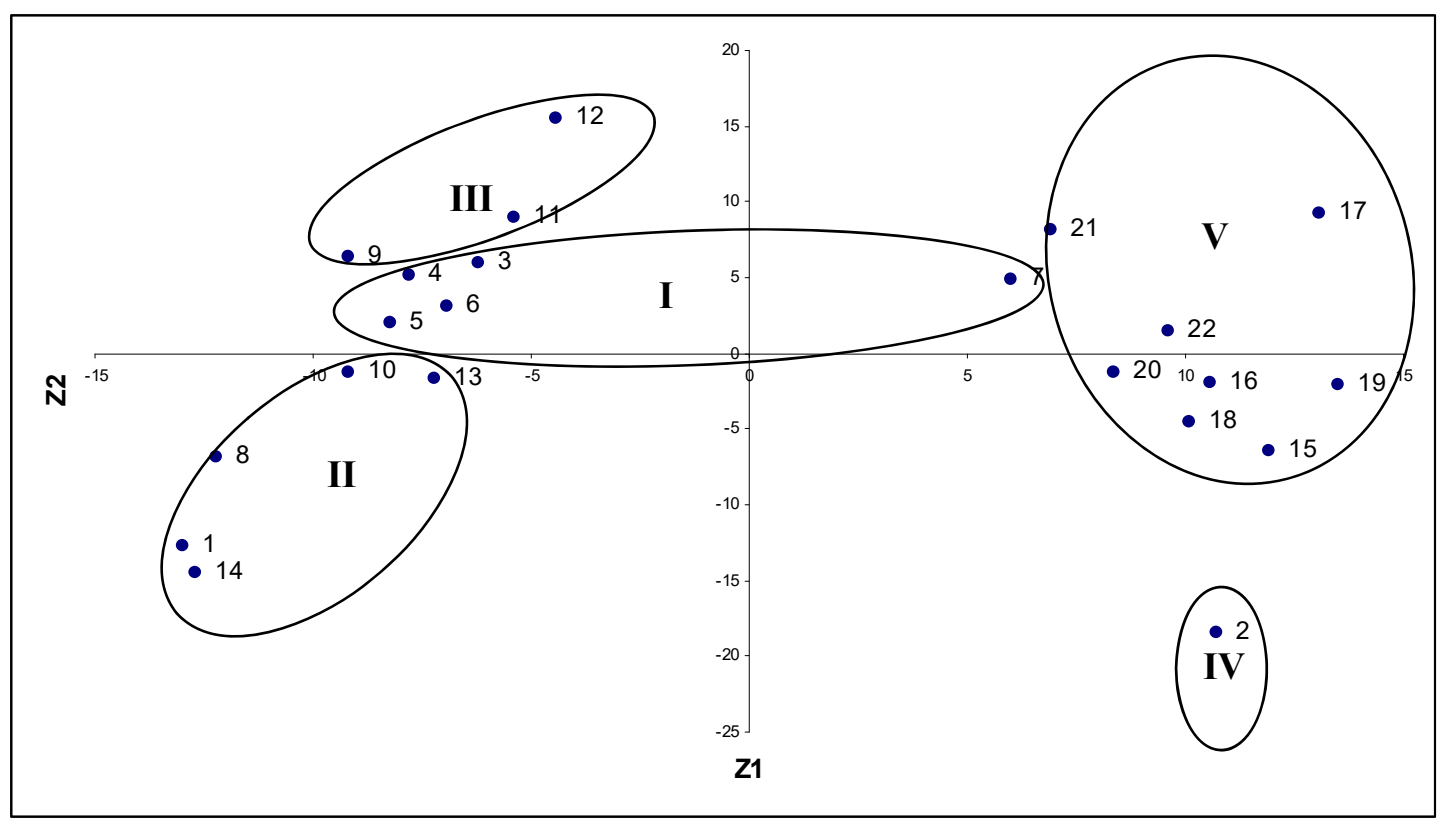

Figure 1. Scatter distribution of 22 genotypes of bottle gourd based on their principal component scores

Table 4. Latent vectors for 13 principal component characters of 22 genotypes of bottle gourd

\begin{tabular}{llcc}
\hline Sl. No. & Characters & Vector-I & Vector-II \\
\hline 1. & Days to $1^{\text {st }}$ harvest & 0.2268 & 0.3592 \\
2. & Days to edible fruit maturity & 0.1172 & -0.3685 \\
3. & Fruiting duration (days) & 0.1774 & -0.0642 \\
4. & Fruit length $(\mathrm{cm})$ & 0.3327 & 0.0539 \\
5. & Fruit diameter $(\mathrm{cm})$ & 0.3406 & 0.2922 \\
6. & Fruit exocarp thickness $(\mathrm{cm})$ & 0.3243 & 0.1041 \\
7. & Fruit endocarp thickness $(\mathrm{cm})$ & 0.3306 & 0.2992 \\
8. & TSS $(\%)$ & 0.0107 & -0.0169 \\
9. & Branches per plant & -0.3068 & 0.3080 \\
10. & Vine length $(\mathrm{m})$ & -0.2940 & 0.3854 \\
11. & Fruits per plant & -0.3825 & 0.1539 \\
12. & Fruit weight $(\mathrm{kg})$ & 0.2641 & 0.3445 \\
13. & Yield per plant $(\mathrm{kg})$ & -0.2557 & 0.3955 \\
\hline
\end{tabular}

\section{Conclusion}

Generally crosses involving parents belonging to most divergent clusters are expected to give maximum heterosis and creates wide variability in genetic architecture. However, for a practical plant breeder, the objective is not only obtaining high heterosis but also to achieve high level of production with the shortest possible time. In the present study the maximum distances existed between cluster III and cluster IV. But the cluster III does not contain good mean values performances. Intermediate diverse parents have the more chance to contribute heterosis in the subsequent generations. To select cluster for obtaining more heterotic genotype three pairs of clusters to be considered, which were cluster I and IV, clusters I and V, clusters I and II. Considering yield performance, cluster distance and cluster mean the genotypes LS03, LS04, LS05, LS06, LS07 from cluster I, the genotypes LS01, LS14 from cluster II and the genotypes LS15 from cluster V may be considered better parents for future hybridization programme. 


\section{References}

1. Anonymous. 2017. Year Book of Agricultural Statistics of Bangladesh 2016. Bangladesh Bureau of Statistics, Ministry of Planning, Government of Peoples Republic of Bangladesh, Dhaka, Bangladesh. pp 249-290.

2. Bashar A., Hossain M.K., Hasan R., Islam S., Huque A.K.M.M., and Alam N., 2016, Breeding potential of common eggplant (Solanum melongena L.) using divergence analysis, Bangladesh Journal of Botany, 45(1): 109115

3. Datta S., and Das L., 2013, Characterization and genetic variability analysis in Capsicum annuum L. germplasm, SAARC Journal of Agriculture, 11(1): 91-103

4. Datta S., and Jana J.C., 2011, Studies on genetic divergence in chilli (Capsicum spp.) under sub Himalayan tracts of West Bengal, Journal of Crop and Weed, 7(1):44-48

5. Farhad M.I., Hasanuzzaman M., Biswas B.K., Arifuzzaman M., and Islam M.M., 2010, Genetic divergence in chilli (Capsicum annuum L.), Bangladesh Research Publications Journal, 3(3): 1998-2003

6. Guerra E.P., Destro D., Miranda L.A., and Montalván R., 1999, Parent selection for intercrossing in food type soybean through multivariate genetic divergence, Acta Scientiarum Agronomy, 21(3): 429-437

7. Hasan R., Huque A.K.M.M., Hossain M.K., and Alam N., 2015, Assessment of genetic divergence in Chilli (Capsicum annuum L.) genotypes, Plant Gene Trait, 6(3): 1-5

8. Indra P., Peter K.V., and Unnithan V.K.G., 2000, Divergence in chilli, Spice India, 13 (4):15-20

9. Jagadev, P N, K.M. Shamal and L. Lenka. 1991. Genetic divergence in rape mustard. Indian J. Genet. Pl. Breed. 51:465-466.

10. Mahalanobis P.C., 1936, On the generalized distance in statistics, Proceedings of the National Institute of Sciences of India, 2: 49-55

11. Mahalanobis, P.C., 1936. On the the generalized distance in Statistics. Proc. Natl. Inst. Sci. India. 2: 49-55.

12. Masud. M.A.T., Chowdhury, M.A.Z., Hossain, M.A and Hossain, S.M.M., 1995. Multivariate analysis in pumpkin (CucurbitamoschataDueh ex Poir). Bangladesh Journalof Plant Breedingand Genetics, Vol. 8 No.1 \& 2, pp.45-50.

13. Quamruzzaman, A.K.M., Rahman, M. H, Nazrul Islam, Md,,Rahman, S.M. L. and Sarker, B.C., 2008b. Genetic diversity in land races of ridge gourd, Bangladesh Res. Pub. J. 1(1): 5-8.

14. Quamruzzaman, A.K.M., Rashid, M.A, Ali, M.M, Alam, A.K.M. M, and MashiurRahman, M., 2008a. Genetic diversity in bitter gourd (Momordicacharantia L.). Bangladesh J. Agril. Res., 33(1): 129-134.

15. Rao, C.R. 1952. Advanced Statistical Method in Biometrics Research. John wiley and sons, New York. p. 390.

16. Shidhu J.S., Ahmed S., Sing M.P., and Sing P.K., 1989, Multivariate analysis in blackgram (Vigna mungo L.), Legume Research, 12(1): 35-37

17. Singh, R.K. and Chaudhury, B.D., 1985. Biometrical methods in quantitative genetic analysis.Kalayonipulishers. New Delhi. p. 318.

18. Sreelathakumary I., and Rajmony L., 2004, Genetic divergence in chilli (Capsicum annuum L.), Indian Journal of Horticulture, 61(2): 137-139

19. Yatung T., Dubey R.K., Singh V., and Upadhyay G., 2014, Genetic diversity of chilli (Capsicum annuum L.) genotypes of India based on morpho-chemical traits, Australian Journal of Crop Science, 8(1):97-102. 